\title{
The Improvement Of The Corporate Logistics System In Exporting Vegetables And Fruits
}

\section{Salihov Saidamir Alisher ugli}

$\mathrm{PhD}$, Tashkent State University of Economics, Uzbekistan,

Article History: Received:11 January 2021; Accepted: 27 February 2021; Published online: 5 April 2021

Abstract: This article discusses the concepts of a corporate logistics system, about the rules, how the company's logistics strategy should be aimed at supporting the corporate strategy in order to optimize the company's resources when managing material and related to flows. The concepts shown can be used by all specialists.

Key words: corporate logistics, firm, strategy, economic environment, integrated growth, assortment, services, business, marketing, consumer, demand, production

\section{Introduction}

Corporate logistics is a form of inter-company logistics that develops within the framework of integrated vertical, horizontal and mixed structures. It carries out the processes of exchange of goods and (or) activities that differ in the nature of the relations between their participants, depending on the degree of integration.

Any company (firm) builds its business on the basis of a developed corporate strategy that allows it to achieve long-term goals. The choice of this or that strategy is dictated by both the corporate mission and the current state of the production and financial activities of the company, and the influence of the external and internal economic environment. If a company strives for a long-term presence in the market, then, as a rule, it uses a growth strategy: for example, a concentrated growth strategy (increasing the range of goods and / or services and expanding the sales geography); integrated growth (cooperation and integration with business partners, the creation of holdings, unions, alliances, etc.); diversification strategy, etc.

Materials and Methods

Based on the purpose of logistics in relation to business, the company's logistics strategy should be aimed at supporting the corporate strategy in order to optimize the company's resources when managing material and related flows. It would seem that in these conditions, a logistics strategy should be the same natural element of rategic business planning as marketing, financial, production and other types of

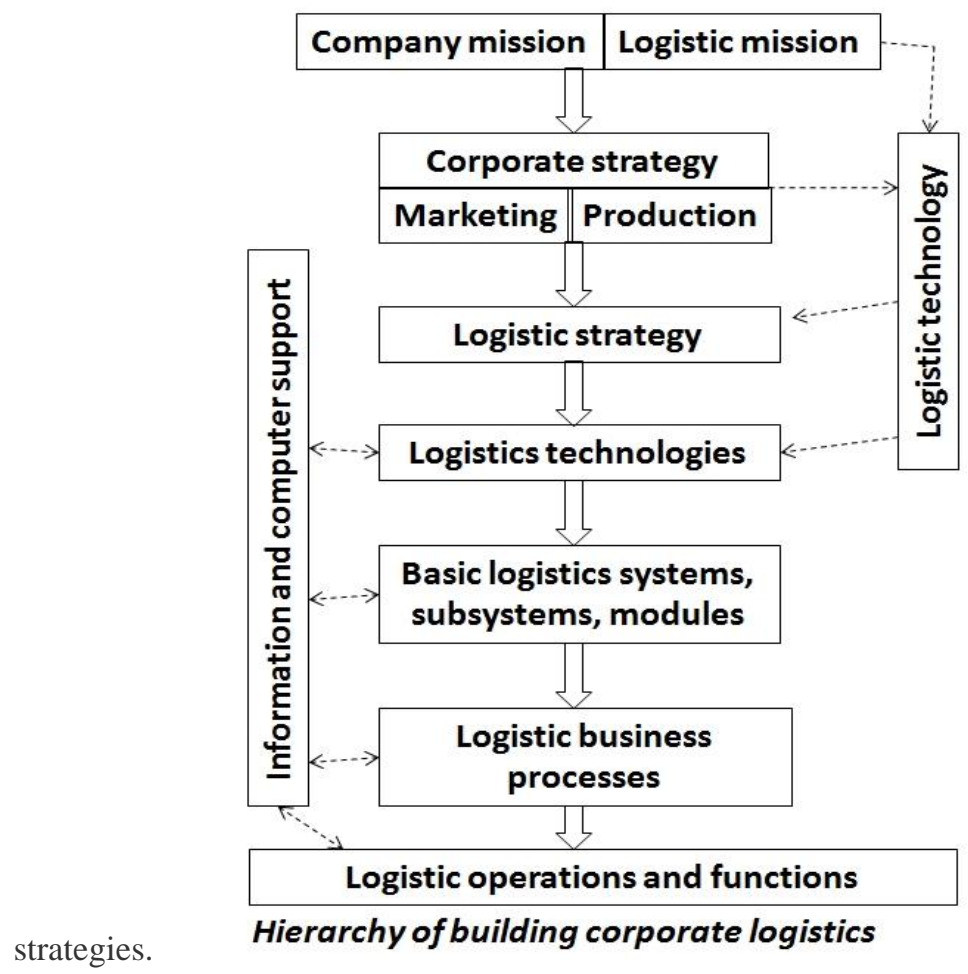

The organization of the corporate logistics system (LS), including for the export of vegetables and fruits, is based on a certain hierarchical structure. 
At the top level of the hierarchy are the mission and corporate strategy of the company, on the basis of which the following are consistently formulated: logistics concept - mission - strategy -technology - subsystem, etc.

The most modern and rapidly developing business concept of integrated logistics is currently used by many leading companies in the world. Its essence lies in the consideration of logistics as a management tool, integrated material flow to achieve business goals. It reflects a new understanding of business, where individual firms, organizations, systems are considered as some centers of logistics activity, directly or indirectly connected in a single integral process of managing the main and accompanying flows for the highest quality customer satisfaction in accordance with their specific needs and business goals.

When optimizing management at the micro level within the enterprise, it is important to proceed from the conditions for optimizing the drug as a whole. The desire to unite supply, production, distribution is the only perspective in addressing issues of achieving goals within the drug. This makes it possible to achieve goals within the drug. This makes it possible to obtain accurate information about the status and location of a product / service at any time: information about the production process and the entire distribution network.

Among the large number of logistics strategies used by companies, there are several basic ones that are most widely used in business when building a LAN (table). Logistics strategies are built on the basis of optimizing one key indicator, for example, total logistics costs, quality of service, productivity, etc. However, in this case, it is necessary (as for most single-criterion optimization problems) to introduce restrictions on other indicators that are significant from the point of view of the firm's strategy. For example, to minimize the overall logistics costs, such an indicator will be the quality of the logistics service. The more significant the requirements of consumers for the quality of service, the higher should be the logistics costs.

\begin{tabular}{|c|c|}
\hline $\begin{array}{l}\text { Strategy to minimize overall logical } \\
\text { overhead }\end{array}$ & $\begin{array}{l}\text { - the optimization of operational logistic costs in individual } \\
\text { logistics functions; } \\
\text { - the optimization of inventory levels in the logistics system; } \\
\text { - the selection of optimal options "storage - transportation"; } \\
\text { - the optimization of solutions in individual functional areas } \\
\text { according to the criterion of minimum logistics products, etc. }\end{array}$ \\
\hline $\begin{array}{l}\text { Strategy for improving the quality } \\
\text { of logistics services }\end{array}$ & $\begin{array}{l}\text { - the improving the quality of logistics operations and functions } \\
\text { (transportation, warehousing, cargo handling, packaging, etc.); } \\
\text { - the logistic support for pre-sales and after-sales service; } \\
\text { - the value-added logistics service; } \\
\text { - the using of logistics technologies to support the product life } \\
\text { cycle; } \\
\text { - the creation of a quality management system for logistics } \\
\text { services; } \\
\text { the certification of the proprietary quality management system in } \\
\text { accordance with national and international standards. }\end{array}$ \\
\hline  & $\begin{array}{l}\text { - the optimization of the configuration of the logistics network; } \\
\text { - the direct delivery of goods to consumers; } \\
\text { - the using of public warehouses; } \\
\text { - the using of logistics intermediaries; } \\
\text { - the using of technology "just in time"; } \\
\text { the optimization of the location of logistics infrastructure } \\
\text { facilities, etc.; }\end{array}$ \\
\hline Logistics outsourcing strategy & $\begin{array}{l}\text { - make-or-buy decision; } \\
\text { - the focusing the company on its core functions; } \\
\text { - the optimization of the choice of sources of external resources; } \\
\text { - the optimal location of production facilities and infrastructure } \\
\text { facilities; } \\
\text { - leveraging supplier investment and innovation; } \\
\text { the optimization of the number of logistic intermediaries and } \\
\text { their functions. }\end{array}$ \\
\hline
\end{tabular}

The problem of implementing the strategy for minimizing total logistics costs is complicated by the weak formalization of the parameters of the quality of logistics services and the subjectivity of its assessment by consumers.

The goal of taking into account as many key factors as possible in the formed logistic strategy leads to the need to apply multi-criteria optimization, which significantly complicates the task. As indicated, the chosen 
logistics strategy should, on the one hand, correspond to the corporate strategy, and on the other, be based on a certain logistics concept.

In modern conditions, when on the one hand there is always the issue of the urgency of food security around the world, and this factor is further intensified by the pandemic period, it is important to provide the entire population of the world with the necessary vitamins, natural products that contribute to the protective immunity of the human body. However, at different stages of the fruit and vegetable production and marketing chain, there are still many constraints that need to be removed in order to realize the existing export potential:

- Restrictions at the level of production / post-harvest processing / marketing: limited production volumes and difficulties with the formation of large consignments due to small-scale fruit production;

- Low quality or insufficient amount of material and technical resources;

- Significant skills and capacity gaps along the production and distribution chain;

- Weak level of development of cold chains and storage systems, including in the farms themselves;

- High level of informality and non-transparency of relations in supply chains;

- Technical barriers or institutional constraints;

- Poor logistics in agriculture;

- Low level of development of electronic commerce.

- The world market demands stable quality and volume of fresh fruit supplies from exporting countries;

- Entering the world market is possible only if there are modern quality control systems, well-functioning logistic schemes, compliance with strict requirements both in the production of products and at subsequent stages, in order to ensure compliance with strict food safety standards adopted in the world market;

- The fragmentation and competitive structure of the Chinese fruit markets requires constant contact with Chinese partners on the ground;

- Consumers value attractive packaging and products with recognizable brands.

Results and Discussions

The main competitor of Uzbekistan in this area is Turkey, which has already won a strong position in the retail markets. One of the factors of its success lies in its ability to guarantee the quality, range, packaging and volume of products in accordance with the needs of the retail trade. The supply of large quantities of quality fruit can only be ensured by integrating the country's small fruit producers into value chains, and modern internationally recognized food safety and quality systems need to be established.

How to avoid quality losses? How to preserve the freshness, aroma, and taste of the fruit? How to extend the shelf life of vegetables and fruits? The quality in the delivery of fruits and vegetables raises a lot of complaints from wholesale and small wholesale importers, suppliers, as well as from retail chains and stores. Products often arrive spoiled or quickly deteriorate in the warehouse or on shelves. The carrier protects himself. Shows a thermograph, confirming compliance with the temperature regime, a tachnograph that the car was traveling 60 $\mathrm{km} / \mathrm{h}$ and even a satellite map of movement, where the car was driving only along good tracks. We argue about the temperature regime of goods, which is violated during loading, for example, if fruits or vegetables taken out of the warehouse stand for 2-3 hours on a street ramp, and then are loaded into a car that has been standing all this time with the doors of the refrigerator trailer open. That the refrigerator maintains the temperature, and does not freeze, cool or heat. Those modern trailer shock absorbers are not a rutted cart. That the shipping packaging does not protect the fruits / vegetables from jolts while driving, etc. At the shipment, we put the receiver, fixing the external quality of the goods purchased and loaded into the machine. But losses from spoilage of agricultural products on the way from producer to buyer do not decrease.

Producers and exporters of the EU countries, Turkey, Australia, Latin America and Africa, China annually supply hundreds of thousands of tons of foreign fruits and vegetables from all over the world.

And we all forget about one more factor - the compatibility of products, both among fruits or vegetables, and among themselves during transportation and storage. Because some types and conditions, even of their shortterm storage before transportation or during transportation, can trigger mechanisms causing accelerated deterioration.

The import suppliers and retailers, when purchasing directly from abroad or from wholesale suppliers, in order to save time and delivery costs, form a shipped batch of different assortments or varieties of agricultural products and from different storage and shipment locations. However, mixed storage or transportation of several types of agricultural products requires a professional approach. The fact is that some products, due to their specific characteristics, can harm others. 
International transportation of vegetables and fruits and transportation (16-21 tons in a thermo - or a refrigerator / container), according to the loading option, are divided into two types:

- The same type, for example, only apples, only pears or bananas, or only tomatoes, only garlic, etc.,

- Assortment, when in the car, they can load bananas with pears and add, for example, tangerines or avocados, lychees, mangoes.

\section{Transport: packing and loading}

All vegetables and fruits are transported in specialized vehicles equipped with refrigeration units with a thermograph. The trailer must be disinfected before loading.

The refiner maintains a temperature regime. When loading, do not hammer the container tightly and to the ceiling, it is necessary to leave gaps of about $3-5 \mathrm{~cm}$ between every two or three rows, at least $30-50 \mathrm{~cm}$ to the ceiling and there should also be channels at the bottom so that air envelops all the boxes. Otherwise, no one will ensure uniform temperature maintenance in the cargo compartment.

Transportation of vegetable and fruit fruits is carried out in safe, environmentally frie ndly packaging: plastic wrap or specialized paper (some types are transported in shavings). The main purpose of packaging is to prevent friction and collision of fruits, since these processes can further adversely affect the quality of the product. In addition, the harder fruit should be at the very bottom, while the softest and most vulnerable at the top.

Transportation is carried out at a speed of up to $90 \mathrm{~km} / \mathrm{h}$ on federal highways and not more than $60 \mathrm{~km} / \mathrm{h}$ on regional ones, this guarantees safety from impacts.

\section{Temperature and humidity}

As a rule, the secret of safe transportation is to set the temperature a few degrees higher or lower than recommended after closing the trailer doors for 2-4 hours. This allows the box body to be set to the same temperature as the cargo in the warehouse and to minimize the likelihood of cold or heat damage to the most sensitive fruits and vegetables. Similarly, it is necessary to achieve average readings of a hygrometer (moisture meter), since humidity is the second most important indicator that affects the safety of vegetables and fruits.

\section{Ethylene compatibility - something that is always forgotten}

The fruits of many crops, even during storage, actively release ethylene. It is a colorless gas with a faint odor that is difficult to distinguish due to the aroma of fruits and vegetables. The only difference is that some emit a lot of ethylene, others less. Some cultures are more influenced by it, others less. Under its influence there is an active ripening of fruits plucked in a state of even incomplete ripeness. Ethylene can have a detrimental effect if the vegetable / fruit are adjacent to crops whose fruits have already reached the optimum degree of ripeness. Separate storage and transport of ethylene-releasing products is required to maintain comfortable conditions. This is often not possible due to economic inefficiency. Therefore, it is necessary to place "dangerous" crops at the maximum distance from the rest of the fruits. But, even if you strictly follow all the above recommendations, you can get a spoiled product or start some products into self-acceleration, the effect of which may not be obvious during unloading, but will be visible during subsequent storage in a warehouse or on store shelves. So, for example, you cann ot carry and store bananas with apples or pears as bananas cannot withstand being together even more than for 2 days.

By the way, ethylene is not the only factor to be considered. It's no secret that various types of vegetables and fruits are treated with chemical compounds in order to extend their shelf life. All fruit and vegetable crops are exposed to methyl bromide or fungicides prior to transportation and individual fruits can be further processed. Apples and all citrus varieties are usually sprayed with sulfates, sorbic acid or definol to extend shelf life. It is necessary to take into account the reaction of neighboring crops to additional processing agents and avoid mixing them. It is necessary to consider how the products are 
processed during storage, because during transportation, if they were also from different warehouses, gasification can play a cruel joke.

\section{Smell}

Garlic, onions, potatoes, all varieties of citrus fruits, as well as other strong-smelling crops are capable of emitting strong odors that are transmitted to neighboring fruits. We strongly recommend that you abandon the idea of joint storage and transportation of the above crops with other vegetables and fruits.

Below is a table in which the most popular fruits and vegetables are divided into seven groups. Vegetables from each group are admissible for transportation without loss of taste and appearance.

Oddly enough, not all transport companies are able to fulfill all of the above requirements. And, entrusting the case to non-professionals or specialists who are not distinguished by responsibility, you risk additional costs, jeopardize not only the supply, but also your business reputation, and even worse the health of your customers.

Recently, survey services have become increasingly popular, the capabilities of which are neglected by most customers. This allows you to completely eliminate the likelihood of losses during the loading of goods, their transportation and unloading at the customer's warehouse. Specially trained people (surveyors) gradually control all movements of the goods, as well as its quality and compliance with standards during loading and throughout the entire delivery. Despite their low cost, such services allow 99\% to eliminate the likelihood of product spoilage and reduce costs. Thus, we can conclude that transportation and survey services are the expense item on which it is not recommended to save money. By reducing losses and investing in supply today, you increase profits and customer loyalty.

\section{Corona virus poses logistical challenges for food exporters}

In connection with the 2019-coronavirus pandemic, many states are taking additional security measures, which affect the mode of operation of individual companies, seaports and terminals, and leads to disruptions in shipping schedules.

The introduction of shorter working days is accompanied by a drop in production volumes. The entire industry has already faced a labor shortage due to restrictions on the entry of foreign citizens.

Suppliers of agricultural products were the first to face problems due to the corona virus. In January and February 2020, Chinese importers notified contractors about delays in loading and unloading operations in ports, idle ships, accumulation of containers with cargo at terminals, and a lack of energy resources to connect refrigerated containers.

\section{Closed borders}

Around the world, the situation is developing according to a negative scenario in all countries such as Italy, Iran and South Korea at the moment. All of Europe and the United States are taking unprecedented epidemiological safety measures. In the 11th week of 2020 (March 9-15), several EU transport and logistics companies sent an open letter to the governments of Italy and other countries about the impact of the imposed restrictions on logistics operations and the economy of individual market players.

For example, the railway operator Swiss terminal has calculated that the number of freight containers shipped from Italy has decreased by $10 \%$. The ban on crossing borders between regions for vehicles is reflected not only on the traffic flow, but also on the work of inspectors, customs officials and other participants in logistics operations.

The Government of India has decided to close the country: until April 15, all issued visas, except diplomatic ones, have been suspended. Everyone who came from countries where outbreaks of corona virus infection have been registered are placed in a 14-day quarantine. The same procedure is established in Israel, and it applies to virtually all ships calling at the ports of the country. Quarantine restrictions are adopted in the UK, Spain, the Netherlands, Norway, the United States and other advanced economies.

Consequently, logistical disruptions typical for China in the first two months of 2020 may start in Europe and other regions of the world, including Uzbekistan.

Problems when importing fresh vegetables and fruits

Fresh vegetables and fruits, as well as citrus fruits, are surprisingly useful for our body at any age and at any time of the year. For this reason, we get sick less during the period of epidemics; we got rid of scurvy - a disease of early sailors and vitamin deficiency. 


\section{Problem \# 1}

Fresh vegetables and fruits are transported over long distances under a strictly defined temperature regime in specially equipped refrigerators. And sometimes, even with special gas fillers, thanks to which fresh vegetables and fruits retain their appetizing appearance for the longest time. For example, the delivery of perishable goods was from Europe in refrigerated trucks, in particular from the largest Dutch port of Rotterdam. When a car refrigerator moves, the refrigerator, which maintains a certain temperature regime for 3-4 days, dries the air that envelops the living product. Shrinkage can be significant over the period of moving from the distribution point. It can be from $10 \%$ to $15 \%$ of the weight of the transported goods. In this regard, experienced European suppliers (sellers) add excess weight to the standard box (for shrinkage during transportation so that the final recipient gets exactly his ordered weight and assortment. The sender loads, for example, instead of 13 $\mathrm{kg}$ in a standard box, puts $13.2 \mathrm{~kg}$. By the way, in Europe it is not customary to take into account the weight of fresh vegetables and fruits when sold to wholesalers, they take them into account first of all in boxes, and for reference, in kilograms. A standard $82 \mathrm{cc}$ refrigerator contains 32 euro pallets. One euro pallet accommodates, with an average load, from 60 to 100 boxes with perishable goods. The loading weight of each cardboard box, depending on the assortment of goods, ranges from $2.5 \mathrm{~kg}$ up to $18.5 \mathrm{~kg}$. In rare cases, the box can be loaded for $20 \mathrm{~kg}$. The weight of a standard load in a car refrigerator with fresh vegetables and fruits can range from 16-18 tons. For citrus fruits, the transported weight can range from 26 to 28 tons per refrigerator. In rare cases, the transported weight of a citrus fruit can reach up to 30 tons in a refrigerator. But this is already a whole refrigerated road train with trailed refrigerators.

As a result, the overweight for one standard refrigerator or euro van with vegetable and fruit products can be from 500 to $700 \mathrm{~kg}$ or more.

\section{Problem \# 2}

Another problem is cardboard boxes, that is, the main container for transporting fresh vegetables and fruits. Cardboard boxes perfectly absorb moisture, and in this regard, a cargo moving for several days to a Russian consumer may have an overweight, the same 100-200 grams on the box. This usually happens if the refrigerator is not in order: there is air access from the outside, and instead of maintaining a certain temperature and drying the goods, it creates condensation, which is instantly drawn into cardboard boxes like a sponge. And when such a refrigerator arrives for customs clearance at the temporary storage warehouse, it is not difficult to find a violation with the importer of the goods. Usually, customs officers, seeing that there is no order with the refrigeration system of a car, are forced to carry out the preponderance of all perishable goods on precise electronic scales. In such a situation, the preponderance of the perishable rate, laid down for shrinkage, is usually revealed, in addition to the overweight that arose during the abnormal operation of the refrigerator itself, which saturated the cardboard boxes with additional unaccounted for moisture. The result is usually as follows. Or a foreign trade participant must pay a fine for violation of customs clearance. And he has an overweight in the import cargo, on the weight of which customs duty in the form of customs duty and VAT should be charged. Or you have to explain for a long time with the customs officers why everything turned out so badly. And the life of the fruit is inexorably shortening. There is also a third way, pay and drive.

\section{Problem \# 3}

Another problem is Control of the Customs Value (CCV) of imported goods! The CCV system is ranked in kilograms, not boxes or cubic meters. This CCV system was adopted based on the ideal conditions for the exact delivery of goods in Europe, the ideal conditions for the transportation of goods over long distances, and the ideal conditions for the perishable goods to overcome our border borders in the areas of MAP (international road crossings) without queues and hesitations! As you understand, our life is far from ideal! So, if the weight in the refrigerator is exceeded, and the value indicated in the invoice does not take into account this excess, but is on the verge of customs risk, the problem of the underestimated value of the goods arises. If the delivered weight is divided by the invoice value, it turns out that a kilogram of fruit will cost less than the permitted one. Therefore, the legislative bodies of the Russian Federation not long ago made changes to the criminal code, excluding this offense from it with a preponderance of fruit, while translating it into an administrative offense. This problem could have been avoided in the bud by adopting the relevant European technical regulation for the transport of fresh vegetables and fruits, taking into account shaking and shrinkage.

And how many nerves could be saved from our valiant foreign trade participants and distributors of perishable goods!?

\section{Problem \# 4}

Fresh vegetables and fruits, including citrus fruits, brought from abroad, are exchange commodities. And as we well know, everything that is traded on world stock exchanges during the season tends to both increase and decrease in price. Goods in cars with vegetables and fruits can reach the desired region in 3-4 days. 
In the worst case, it takes 5-6 days. During this period, both a jump in price and a drop in prices can occur on the exchange trading in fresh vegetables and fruits. Moreover, the drop in wholesale prices for fresh vegetables and fruits can be twofold or more. And now, imagine a foreign trade participant on our border, when such a drop in prices on the stock exchange took place. He has an invoice in his hands at the purchase price of goods for $\$ 1$ per $1 \mathrm{~kg}$, and the real exchange price, at the moment, is $\$ 0.5$ per $1 \mathrm{~kg}$. The customs require from the participant of foreign economic activity customs duties from $5 \%$ to $10 \%$ per $1 \mathrm{~kg}$ from the delivered weight across the border and also VAT with the expensive cost of the goods, that is, for \$ 1 per $\mathrm{kg}$, yesterday. What to do?! In practice, the customs obliges the participants in foreign economic activity to pay at a price not less than the established risk price. At a high price, per unit weight of the imported goods. Usually, this price is determined by the relevant customs office for a given period or season.

\section{Conclusion}

This article could not cover all aspects of the supply chain of fresh vegetables and fruits to the global market. Since the price of a product in the process of its appearance on the counter is influenced by additional factors, in particular, the cost of delivery and insurance of the product in transit. The price of imported goods also depends on the size of the batch of goods purchased from a foreign supplier. And also, on whether an advance payment has been made for imported goods. Either this delivery is formalized by a Russian importer as a trade credit, or payment will be made after the sale of the goods.

However, it is important for everyone, especially for the poor, so that vegetables and fruits can be bought at affordable prices in stores and supermarkets.

1. The customs service probably needs to improve the methodology for calculating and calculating customs duties and VAT for the export category of goods: fresh vegetables and fruits and their processed products.

2. It would be nice to try to negotiate duty-free export of vegetables and fruits with foreign importing countries.

3. It would be progressive to combine the monitoring system of exchange prices for fresh vegetables and fruits at foreign customs offices with the possibility of real-time correction of customs risks.

4. Apparently, it is possible to link the results of trading on international exchanges, with the use of customs risks and the appointment of customs duties on perishable commodity items, at the time customs duties are charged during customs clearance.

\section{References:}

1. Strategies Of Corporate Logistics System . V.I. Burakov Doctor Of Economics, Professor Of The Department Of Logistics And Commerce Bulletin Istu №12 (95) 202023

2. D.N. Telitchenko. Organizational And Economic Model Of Development Of The Logistic Center Of Vegetables

3. The Decisions of the Supreme Eurasian Economic Council of December 19, 2011 No. 17, of December 19, 2012 No. 25 and of December 24, 2013 No. 59) "The list of sensitive goods in relation to which the change in the import customs duty rate is adopted by the EEC Council".

4. M.F. Atoyeva. Interdisciplinary relations in physics course at specialized secondary education. The Way of Science. - Volgograd, 2016. -№9 (31). - P.22-24.

5. M.F. Atoyeva. The significance of periodicity at teaching physics. The Way of Science. - Volgograd, 2016. -№ 10 (32). - P.62-64.

6. Атоева М.Ф. Эффективность обучения электродинамике на основе технологии периодичности. The Way of Science. - Volgograd, 2016. -№ 10 (32). - P.65-66.

7. M.F. Atoyeva. Use of Periodicity in Teaching Physics. Eastern European Scientific Journal. -DüsseldorfGermany, 2017. № 4. -P. 35-39.

8. M.F. Atoyeva. Didactic foundations of inter-media relations in the training of university students. International Scientific Journal. Theoretical \& Applied Science. p-ISSN: 2308-4944 (print) e-ISSN: 2409-0085 (online). Year: 2020 Issue: 06 Volume: 86, P. 124.

9. M.F. Atoyeva, R. Safarova. Pedagogical integration as a means of forming professionally important qualities among students of a medical university. Academicia. ISSN: 2249-7137 Vol. 10, Issue 8, August 2020. Impact Factor: SJIF $2020=7.13$ ACADEMICIA: An International Multidisciplinary Research Journal https://saarj.comэ.

10. Atoeva Mehriniso Farhodovna. Pedagogical Tests As An Element Of Types Of Pedagogical Technologies. The American Journal of Applied Sciences, 2(09), (TAJAS) SJIF-5.276 DOI-10.37547/tajas Volume 2 Issue 9, 19.09.2020. ISSN 2689-09. 92 The USA Journals, USA www.usajournalshub.com/index.php/tajas 164169. Имп.5.2. 
11. Atoeva Mehriniso Farkhodovna. The problems of preparing students for the use of school physical experiment in the context of specialized education at secondary schools. European Journal of Research and Reflection in Educational Sciences, UK, Vol. 8 No. 9, 2020 ISSN 2056-5852. P.164-167. Sites:

https://google.com, https://www.bibliofond.ru/ 